\title{
Postpartum trend in blood pressure and renal function in women with severe preeclampsia and eclampsia: $A$ prospective cohort-study at Mulago hospital, Kampala, Uganda
}

Kasereka Muteke 1ף, Jolly Beyeza ${ }^{2 \pi}$, Milton W Musaba ${ }^{3 \pi}$, Julius Wandabwa ${ }^{3 \pi}$, Paul Kiondo ${ }^{1 \pi}$ *

'Department of Obstetrics and gynecology, College of Health Sciences, Makerere University,

P.O BOX 7072, Kampala, Uganda, East Africa.

${ }^{2}$ Department of Obstetrics and Gynecology, Mulago National Referral Hospital, P.O Box 7051,

Kampala, Uganda, East Africa

${ }^{3}$ Department of Obstetrics and Gynecology, Faculty of Health Sciences, P.O Box 1460, Mbale, Uganda.

*Corresponding Author

Email address: kiondop@yahoo.com (PK)

9These authors contributed equally to this work

docmuteke@gmail.com (KM)

kiondop@yahoo.com (PK)

jbeyeza@yahoo.com (JB)

gjwandabwa@yahoo.com (JW) 
bioRxiv preprint doi: https://doi.org/10.1101/562934; this version posted February 27, 2019. The copyright holder for this preprint (which was not certified by peer review) is the author/funder, who has granted bioRxiv a license to display the preprint in perpetuity. It is made available under aCC-BY 4.0 International license.

miltonmusaba@gmail.com (MWM) 


\section{Abstract}

\section{Background}

3 Preeclampsia/Eclampsia is a multisystem disorder of pregnancy with kidney involvement. Our

4 objective was to assess the postpartum trend in blood pressure, renal function and proteinuria 5 and, to investigate their predictors in Ugandan women with severe preeclampsia and eclampsia.

\section{Methods}

7 This was a prospective cohort study that involved 97 women with severe preeclampsia and

8 Eclampsia, conducted at Mulago National referral hospital from August 2017 to April 2018. The

9 clinical and laboratory variables were collected from the women on day1, 7, 21 and day 42 after

10 delivery. Kaplan-Meier Survival analysis, Cox-proportional Regression and Log-Rank tests were

11 used to compare the baseline and the follow-up variables with changes in blood pressure, renal

12 function and urine protein.

\section{Results.}

14 Most women (93.8\%) recovered from hypertension within 6 weeks of childbirth with the mean

15 time to resolution of 2.49 weeks (95\% CI: $2.13-2.82$ ). About $81 \%$ of the women recovered their

16 renal function and the mean time to recovery was 24.54 days (95\% CI: 20.14-28.95). Proteinuria

17 resolved in approximately $84 \%$ of the women and the mean time resolution of urine protein of

1832.85 days (95\% CI: 30.31-35.39). Having multiple pregnancy versus a singleton pregnancy was

19 associated with persistence of hypertension six weeks after child birth (P-value $=0.013)$. 


\section{Conclusion}

21 In this study, the blood pressure and renal function of most women with severe preeclampsia and

22 eclampsia normalized within six weeks after childbirth. A special interdisciplinary follow up for

23 patients with preeclampsia/eclampsia by an obstetrician and physician is needed in the

24 postpartum period to reduce the maternal morbidity and mortality associated with this condition

25 in our community.

26

27

28

29

30

31

32

33

34

35

36

37

38

39

40

41 
bioRxiv preprint doi: https://doi.org/10.1101/562934; this version posted February 27,2019 . The copyright holder for this preprint (which was not certified by peer review) is the author/funder, who has granted bioRxiv a license to display the preprint in perpetuity. It is made available under aCC-BY 4.0 International license.

\section{Keys words}

43 Preeclampsia, Hypertension, Proteinuria, Renal dysfunction, Resolution, Postpartum.

44 


\section{Introduction}

47 Preeclampsia is a multisystem human specific pregnancy disorder characterized by new onset

48 hypertension and proteinuria after 20 weeks of pregnancy(1). It affects $2-8 \%$ of all pregnancies

49 worldwide and contributes significantly to maternal, fetal and neonatal morbidity and mortality

50 (2). Preeclampsia with other hypertensive disorders in pregnancy contributed to $14 \%$ of maternal

51 deaths worldwide (3). It is estimated to cause $8 \%$ of the severe maternal morbidity in Uganda is

52 the leading cause of maternal deaths (4). Women with preeclampsia have an increased risk of

53 renal, cerebrovascular and cardiovascular complications after delivery(5). In low resource

54 settings, preeclampsia is an important cause acute kidney injury and contributes to one third of

55 the cases seen in late pregnancy (6). Half of the women with acute kidney injury require dialysis

56 and when dialysis is not available as is commonly the case in many low resource settings, acute

57 kidney injury frequently leads to death of the women. Studies show that women recover their

58 renal function after preeclampsia (7), however, other workers have revealed that women with

59 preeclampsia are at a 5 to 12 -fold increased risk of end-stage renal disease (8) and therefore

60 require prolonged nephrological follow up. The development of renal disease after preeclampsia

61 is not clearly understood. The renal injury may be due to extensive endothelial or podocyte

62 injury (9) seen in women with preeclampsia. This leads to nephron loss and later development of

63 renal disease.

64 Women with preeclampsia on the other hand are at increased risk of cardiovascular disease

65 compared to normotensive women. They therefore require long time follow up regarding

66 hypertension after delivery(10). The mechanisms of developing chronic hypertension is not

67 clear. However, it may be due organ damage or preeclampsia may be a risk factor for later 
68 development chronic hypertension. (1). Studies in Uganda have shown that up to one third of the

69 women with preeclampsia had persistent hypertension after the puerperium $(11,12)$. The

70 predictors for persistent hypertension were participants age $(11,12)$, gestational age at delivery

71 and parity of the mother (12).

72 It is therefore important that women with preeclampsia are followed after the puerperium if the

73 blood pressure and renal dysfunction do not resolve. The purpose of this study therefore was to

74 evaluate the postpartum trend in blood pressure, renal dysfunction and, proteinuria and to

75 determine the factors associated with their resolution in women with severe preeclampsia and

76 Eclampsia in Mulago hospital. 


\section{Methods}

\section{Study design}

80 This was a prospective cohort study conducted from August 2017 to April 2018 in Uganda. This

81 study was approved by the Mulago hospital ethics committee, the Makerere School of Medicine

82 Research and Ethics committee and Uganda National Council for Science and Technology.

83 Written informed consent was obtained from the participants.

\section{$84 \quad$ Setting}

85 This study was conducted at Mulago hospital. Mulago hospital is a national referral hospital for

86 Uganda and serves as the teaching hospital for Makerere University College of Health Sciences.

87 Mulago Hospital delivers about 30,000 women per year and offers antenatal and postnatal 88 services.

\section{Study population}

90 The study population consisted of women with severe preeclampsia and eclampsia who delivered

91 at Mulago hospital during the study period. Women with a known history of hypertension,

92 diabetes mellitus and kidney disease were excluded from the study.

93 Preeclampsia was defined according to the classification by the Working group of National High

94 blood pressure Education program (2000) and the American College of Obstetricians and

95 Gynecologists (2013) (13). Under this classification, hypertension was defined as a systolic

96 blood pressure of $\geq 140 \mathrm{mmHg}$ and/or diastolic blood pressure of $\geq 90 \mathrm{mmHg}$ on 2 occasions at 
97 least 4 hours or more apart. Proteinuria was defined as urine protein of $\geq 300 \mathrm{mg} / 24 \mathrm{~h}$ urine

98 collection or protein/creatinine ratio of $\geq 0.3$ or a dipstick reading of $\geq 2+$. Preeclampsia was

99 taken as hypertension with proteinuria after 20 weeks gestation.

100 A woman with preeclampsia was taken to have severe preeclampsia if she had BP of $\geq 160$ $101 \mathrm{mmHg}$ systolic or $\geq 110 \mathrm{mmHg}$ diastolic, severe headache or visual disturbances, 102 thrombocytopenia of $\leq 100,000 / \mu \mathrm{L}$, aspartate transaminase or alanine transaminase $>2$ times the 103 upper limit with severe epigastric or upper quadrant pain, pulmonary edema or serum creatinine $104 \geq 1.1 \mathrm{mg} / \mathrm{dL}$. A woman with preeclampsia was taken to have eclampsia if she developed a 105 convulsion that could not be attributed to any other cause (14).

106 Sample size

107 We assumed that the persistence of hypertension would be $42.6 \%$ as was found in a study by

108 Kaze et.al (15) and parity as a biggest risk factor for preeclampsia with an odds ratio of 3.71 as

109 was found in a study in Mulago hospital (16). With these estimates a sample size of 97

110 participants would be sufficient with power of $80 \%$ at confidence level of $95 \%$ taking in account

111 of the anticipated loss to follow up of $5 \%$.

\section{Study procedures}

113 The research assistants who were qualified midwives identified women with severe preeclampsia 114 and eclampsia from the labour ward and the high dependence unit of the hospital. They 115 approached the attendants of the women and gave them information about the study. The 116 attendants were conducted through an informed consent procedure and gave a written informed 117 consent. The women later gave informed consent when they improved. Information was obtained 
118 from the attendants and from the abstraction of the charts and later verified from the women

119 when they improved. The eligible participants were recruited consecutively until the required

120 sample size was achieved. The information from the women was collected using an interviewer-

121 administered questionnaire, participants' examination, and biochemical investigations. Urine was

122 collected from the women for urine protein estimation and blood was drawn for serum creatinine

123 measurement.

\section{Follow up}

125 The women were followed for 6 weeks after delivery. The women were reviewed on day 1,7,21

126 and day 42 by the research team. During the review the women were asked about their health and

127 a focused history and examination were done using case record form. The blood pressure was

128 measured, blood was drawn from the women for measurement of serum creatinine and urine for

129 estimation of urine protein. For renal function, a software package was used to estimate the

130 glomerular filtration rate using current serum creatinine, patient race, gender and age of the 131 participant (17). The MDRD calculator was used for determining and classifying the estimated

132 glomerular filtration https://patient.info/doctor/estimated-glomerular-filtration-rate-gfr-calculator

\section{Outcomes}

134 The primary outcome was time to resolution of the blood pressure. Secondary outcomes were 135 time to recovery of renal function and disappearance of proteinuria. The blood pressure was 136 considered normal when it was less than 140/90 $\mathrm{mmHg}$ without any antihypertensive 137 medications for at least one week.

138 Serum creatinine level and estimated glomerular filtration were measured at every visit and were 139 considered normal when the estimated glomerular filtration was $\geq 90 \mathrm{~mL} / \mathrm{min} / 1.73 \mathrm{~m}^{2}$ 
140 Urine protein was considered to have returned to normal if the measurement of spot urine by

141 dipstick was less than $30 \mathrm{mg} / \mathrm{dl}$.

\section{Data analysis}

143 The data were coded and double entered using the Epi-data Version 3.1 and analyzed with

144 STATA version 12. Counts, means, median, percentage and cumulative percentage were used to

145 report the results. Survival analysis with Kaplan-Meier was used to determine time to resolution

146 of hypertension, renal dysfunction and urine protein. Cox- proportional regression and Log rank

147 test were used to determine association of participant variables with time-to resolution of

148 hypertension, renal dysfunction and urine protein. Association was considered statistically

149 significant if it had a P-value of less than 0.05 . 


\section{Results}

153 In this study 97 women with severe preeclampsia/Eclampsia were followed up for 6 weeks after

154 childbirth. The time to resolution of hypertension, renal function and proteinuria, and the 155 associated factors were determined.

156 All the 97 participants had hypertension, 20 were censored: 2 women died, 12 were lost to

157 follow-up by the third visit, and 6 had persistent hypertension by the end of this study.

158 Forty seven participants had abnormal renal functions, 10 were censored: 9 women had 159 persistent renal dysfunction by the end of the study and 1 woman was lost follow up.

160 Finally, 92 had proteinuria: 29 were censored because 15 women had persistent proteinuria by

161 the end of the study and 14 women were lost to follow up (Fig 1).

162 The mean age of the participants was $26.6 \pm 5.4$ years, mean gestation age was $35.9 \pm 4.0$ weeks 163 and a modal parity was 2 with a range of 1-6. 
178 The mean time to resolution of hypertension was 2.49 weeks (CI: 2.13-2.84). The blood

179 pressure decreased over the 6 weeks period of follow-up. Only 6 women $(6.2 \%)$ had persistent hypertension 6 weeks after delivery (Fig 2). The decrease of blood pressure was not affected by

181 the time of onset of preeclampsia $(p=0.426)$, mode of delivery $(p=0.891)$ and the parity of the

182 woman $(\mathrm{p}=0.139)$.

183 After controlling for other variables, having multiple pregnancy versus singleton pregnancy was

184 significantly associated with persistence of hypertension 6 weeks after delivery $(\mathrm{p}$ value $=0.013$ )

185 (Fig 3). Other factors like time of development of preeclampsia, parity and mode of delivery

186 were not associated with persistence of hypertension 6 weeks after childbirth.

187 The mean time for the recovery of the renal function was 24.5 days (95\% CI: 20.14-28.95). The

188 renal function improved during the six weeks of follow up and only $9(19.1 \%)$ women had

189 persistent renal dysfunction at 6 weeks follow-up (Fig 4). There recovery of the renal function

190 was not associated with mode of delivery of the patient $(\mathrm{p}=0.256)$, onset of preeclampsia 
$191(\mathrm{p}=0.180)$, parity of the patent $(\mathrm{p}=0.709)$ and whether the mother delivered single or multiple

192 pregnancy $(\mathrm{p}=0.147)$.

193 The mean time for the resolution of proteinuria was 32.9 days (95\% CI: $30.3-35.4)$. Urine protein

194 decreased over the six week follow-up and $15(16.3 \%)$ women had persistent proteinuria by the

195 end of the study (Fig 5). The resolution of proteinuria was not associated with mode of delivery

$196(p=0.267)$, onset of preeclampsia $(p=0.660)$, parity $(p=0.135)$ and single versus multiple

197 pregnancy $(\mathrm{p}=0.075)$.

198 
206 Women with multiple pregnancy were more likely to have persistence of hypertension when

207 compared women with singleton pregnancy $(p=0.013)$ 
bioRxiv preprint doi: https://doi.org/10.1101/562934; this version posted February 27,2019 . The copyright holder for this preprint (which was not certified by peer review) is the author/funder, who has granted bioRxiv a license to display the preprint in perpetuity. It is made available under aCC-BY 4.0 International license. 
bioRxiv preprint doi: https://doi.org/10.1101/562934; this version posted February 27,2019 . The copyright holder for this preprint (which was not certified by peer review) is the author/funder, who has granted bioRxiv a license to display the preprint in perpetuity. It is made available under aCC-BY 4.0 International license.

228 Figure 5: Kaplan-Meier curve of time to resolution of urine protein in women with severe 229 preeclampsia and eclampsia 


\section{Discussion}

234 This was a prospective cohort study in which 97 women with severe preeclampsia and eclampsia

235 were followed after childbirth. In this study, 93.8\% (91/97) of the women recovered from

236 hypertension within 42 days after childbirth. This is in agreement with a study by Wei et al (18)

237 in which $90 \%$ of their patients recovered from hypertension within 60 days after childbirth and

238 Mikami et al (19) in which $90 \%$ of the women required 77 days to recover from hypertension.

239 We considered the blood pressure to be normal if it was less than 140/90mmHg without using

240 antihypertensive treatment for at least one week. In our study most women had an earlier

241 recovery than the women in these other studies by Wei et al (18) and Mikami et al (19). This was

242 probably because most mothers in our study had late onset preeclampsia at a gestational age of

$243 \quad 35.9 \pm 4.0$ weeks. Many studies have shown an association of a late onset of preeclampsia with

244 early recovery of hypertension $(11,19)$. In our study $6(6 / 97,6.2 \%)$ women had persistent

245 hypertension 6 weeks after delivery. This calls for prolonged follow up of women with

246 hypertensive disease in pregnancy. Indeed the Society of Obstetricians and Gynaecologists of

247 Canada clinical practice guidelines recommends follow up after six weeks to ascertain recovery

248 from the effects of pregnancy and childbirth and ensure ongoing care with physicians or

249 nephrologists(20). It has been shown that glomerular endothelial injury due to preeclampsia

250 recovers within four weeks after delivery (21). Therefore women with persistent hypertension six

251 weeks after delivery need adequate follow up to manage the underlying causes.

252 In this study, there was a statistically significant difference in the time to resolution of

253 hypertension between singleton pregnancy versus multiple pregnancy: the time to resolution of

254 hypertension was significantly shorter in singleton pregnancy ( $35.3 \pm 18.6$ days) when compared 
to multiple pregnancy (43.5 \pm 31.4 days). This finding disagrees with what Mikami et. al. (19) found in their study. The normalization of blood pressure was significantly longer in singleton pregnancy than multiple pregnancy.

In this study, 47(47/97, 48.5\%) participants had renal dysfunction after delivery: 24 women $(24 / 47,51.1 \%)$ were in stage $2,18 / 47(38.3 \%)$ in stage 3 and $4 / 47(8.5 \%)$ in stage 4 of chronic kidney disease. At 6 weeks postpartum, 38 women (38/47, 80.9\%) resolved and 9(9/47, 19.1\%) had persistent renal dysfunction: 6 in stage 2 and 3 in stage 3 chronic renal disease. The prevalence of renal dysfunction was higher than $24.1 \%$ that was found by Kaze et al in Cameroonian women (15) and 35.3\% that was found by Prakash et al (6) in Indian women. Renal dysfunction is due glomerular endotheliosis which occurs in women with preeclampsia/eclampsia. Other studies have reported that resolution of the renal lesions may take up to two years (21). In our study, $18.6 \%$ of the women had persistent renal dysfunction six weeks after delivery. This is a reflection of the persistent effect of endothelial damage seen in preeclampsia(22). Most of these women are expected to recover within two years after delivery as this does not indicate chronic disease (23). However, this calls for prolonged follow up with a nephrologist.

We observed persistence of proteinuria of $16.3 \%$ at six weeks after delivery. This was lower than what was found in other studies $(15,19)$. Proteinuria is due endothelial dysfunction which plays a central role in the pathogenesis of preeclampsia (24). It has been shown that circulating soluble fms like tyrosine kinase-1 (sFlt-1) are elevated and these bind circulating vascular endothelial growth factor (VEGF). These have an association with glomerular endotheliosis and proteinuria(25). The resolution of proteinuria may echo the endothelial recovery seen after preeclampsia (26). These results may suggest that the time to resolution of proteinuria may be 
278 dependent on the degree and duration of endothelial cell injury. We expect most of the mothers

279 with proteinuria to recover within two years as has been found in others studies(27). Proteinuria

280 at six weeks does not indicate chronic disease. It most probably a temporary effect of endothelial

281 damage seen in preeclampsia and more invasive investigations should be delayed until two years

282 after delivery. 


\section{Conclusion}

293 In this study, 16.3\% participants had persistent proteinuria, $6 \%$ had persistent hypertension and

294 19.6\% had persistent renal function six weeks after delivery. Special interdisciplinary follow up

295 of the patients with preeclampsia/eclampsia by an obstetrician and a physician after delivery is

296 required to reduce maternal morbidity and mortality associated with preeclampsia/eclampsia in

297 our community.

298

299

300

301 


\section{Acknowledgements}

305 Our thanks go to the staff of Mulago hospital maternal fetal medicine unit, the study participants, 306 and our research team.

\section{Author Contributions}

308 Conceived and designed the study: MK, PK, JB, JW, MWM. Participated in data collection and

309 analysis: MK, PK, JB, JW, MWM, Interpreted the data and drafted the manuscript: MK, PK, JB,

$310 \mathrm{JW}, \mathrm{MWM}$ Reviewed and approved the final manuscript: MK, PK, JB, JW, MWM 


\section{References}

1. Moussa HN, Arian SE, Sibai BM. Management of hypertensive disorders in pregnancy. Women's health. 2014 Jul;10(4):385-404. PubMed PMID: 25259900.

322 2. Jim B, Sharma S, Kebede T, Acharya A. Hypertension in pregnancy: a comprehensive update. Cardiology in review. 2010 Jul-Aug;18(4):178-89. PubMed PMID: 20539101.

3. Say L, Chou D, Gemmill A, Tuncalp O, Moller AB, Daniels J, et al. Global causes of maternal death: a WHO systematic analysis. The Lancet Global health. 2014 Jun;2(6):e323-33. PubMed PMID: 25103301.

4. Okong P, Byamugisha J, Mirembe F, Byaruhanga R, Bergstrom S. Audit of severe maternal morbidity in Uganda--implications for quality of obstetric care. Acta obstetricia et gynecologica Scandinavica. 2006;85(7):797-804. PubMed PMID: 16817076.

5. Hertig A, Watnick S, Strevens H, Boulanger H, Berkane N, Rondeau E. How should women with pre-eclampsia be followed up? New insights from mechanistic studies. Nature Clinical Practice Nephrology. 2008 07/15/online;4:503.

6. Prakash J, Niwas SS, Parekh A, Pandey LK, Sharatchandra L, Arora P, et al. Acute kidney injury in late pregnancy in developing countries. Renal failure. 2010 Jan;32(3):309-13. PubMed PMID: 20370445. 7. McDonald SD, Han Z, Walsh MW, Gerstein HC, Devereaux PJ. Kidney disease after preeclampsia: a systematic review and meta-analysis. American journal of kidney diseases : the official journal of the National Kidney Foundation. 2010 Jun;55(6):1026-39. PubMed PMID: 20346562.

338 8. Paauw ND, Luijken K, Franx A, Verhaar MC, Lely AT. Long-term renal and cardiovascular risk after preeclampsia: towards screening and prevention. Clinical science. 2016 Feb;130(4):239-46. PubMed PMID: 26769659.

9. Garovic VD, Wagner SJ, Turner ST, Rosenthal DW, Watson WJ, Brost BC, et al. Urinary podocyte excretion as a marker for preeclampsia. American journal of obstetrics and gynecology. 2007 Apr;196(4):320 e1-7. PubMed PMID: 17403404.

10. Bellamy L, Casas JP, Hingorani AD, Williams DJ. Pre-eclampsia and risk of cardiovascular disease and cancer in later life: systematic review and meta-analysis. Bmj. 2007 Nov 10;335(7627):974. PubMed PMID: 17975258. Pubmed Central PMCID: 2072042. puerperium among women with pre-eclampsia/eclampsia in Mulago hospital, Uganda. BMC pregnancy and childbirth. 2010 Mar 12;10:12. PubMed PMID: 20222993. Pubmed Central PMCID: 2848130. eclampsia: a prospective cohort study at Mulago Hospital, Uganda. PloS one. 2013;8(12):e85273. PubMed PMID: 24392003. Pubmed Central PMCID: 3877387.

353 13. Hauth JC, Rouse DJ, Spong CY. Williams Obstetrics. New York: MacGraw Hill. 2010.

354 14. Obstetricians ACo, Gynecologists. Hypertension in pregnancy 2013.

355 15. Kaze FF, Njukeng FA, Kengne AP, Ashuntantang G, Mbu R, Halle MP, et al. Post-partum trend in 356 blood pressure levels, renal function and proteinuria in women with severe preeclampsia and eclampsia in Sub-Saharan Africa: a 6-months cohort study. BMC pregnancy and childbirth. 2014 Apr 9;14:134. PubMed PMID: 24712704. Pubmed Central PMCID: 4004513. 
16. Kiondo P, Wamuyu-Maina G, Bimenya GS, Tumwesigye NM, Wandabwa J, Okong P. Risk factors for pre-eclampsia in Mulago Hospital, Kampala, Uganda. Tropical Medicine \& International Health. 361 2012;17(4):480-7.

362 17. Sabatine MS. Pocket medicine: The Massachusetts General Hospital handbook of internal medicine: Lippincott Williams \& Wilkins; 2013.

18. Wei J, Wang $Y, X$ U J, Zhang C, Zhou H, Liu G. Clinical study on the factors affecting the postpartum recovery of patients with hypertensive pregnancy disorders at a Chinese hospital. The journal of obstetrics and gynaecology research. 2017 Mar;43(3):456-61. PubMed PMID: 27935226.

19. Mikami $\mathrm{Y}$, Takagi $\mathrm{K}$, Itaya $\mathrm{Y}$, Ono $\mathrm{Y}$, Matsumura $\mathrm{H}$, Takai $\mathrm{Y}$, et al. Post-partum recovery course in patients with gestational hypertension and pre-eclampsia. The journal of obstetrics and gynaecology research. 2014 Apr;40(4):919-25. PubMed PMID: 24428339. and management of the hypertensive disorders of pregnancy: executive summary. Journal of obstetrics and gynaecology Canada : JOGC = Journal d'obstetrique et gynecologie du Canada : JOGC. 2014 Jul;36(7):575-6. PubMed PMID: 25184972. preeclamptic glomerular injury after delivery. American journal of physiology Renal physiology. 2008 Mar;294(3):F614-20. PubMed PMID: 18199600.

22. Karumanchi SA, Maynard SE, Stillman IE, Epstein FH, Sukhatme VP. Preeclampsia: a renal perspective. Kidney international. 2005 Jun;67(6):2101-13. PubMed PMID: 15882253.

23. Spaan JJ, Ekhart T, Spaanderman ME, Peeters LL. Reduced renal function after preeclampsia does not result from accelerated age-dependent renal function loss. Acta obstetricia et gynecologica Scandinavica. 2010 Sep;89(9):1202-5. PubMed PMID: 20524839.

382 24. Ness RB, Sibai BM. Shared and disparate components of the pathophysiologies of fetal growth restriction and preeclampsia. American journal of obstetrics and gynecology. 2006 Jul;195(1):40-9. PubMed PMID: 16813742.

25. Muller-Deile J, Schiffer M. Renal involvement in preeclampsia: similarities to VEGF ablation therapy. Journal of pregnancy. 2011;2011:176973. PubMed PMID: 21494322. Pubmed Central PMCID: 3066648.

388 26. Ferrazzani S, De Carolis S, Pomini F, Testa AC, Mastromarino C, Caruso A. The duration of hypertension in the puerperium of preeclamptic women: relationship with renal impairment and week of delivery. American journal of obstetrics and gynecology. 1994 Aug;171(2):506-12. PubMed PMID: 3918059832.

392 27. Berks D, Steegers EA, Molas M, Visser W. Resolution of hypertension and proteinuria after preeclampsia. Obstetrics and gynecology. 2009 Dec;114(6):1307-14. PubMed PMID: 19935034. 
N=97 with Preeclampsia/Eclampsia

97 women had hypertension

77 achieved the event

Died $=02$
Persistent: 6
20 were censored

Lost follow up: 12
47 had renal dysfunction

37 achieved the event
92 had urine protein

Lost follow up: 1

Persistent: 9

Lost follow up: 14

Persistent: 15

63 achieved the event Figure 


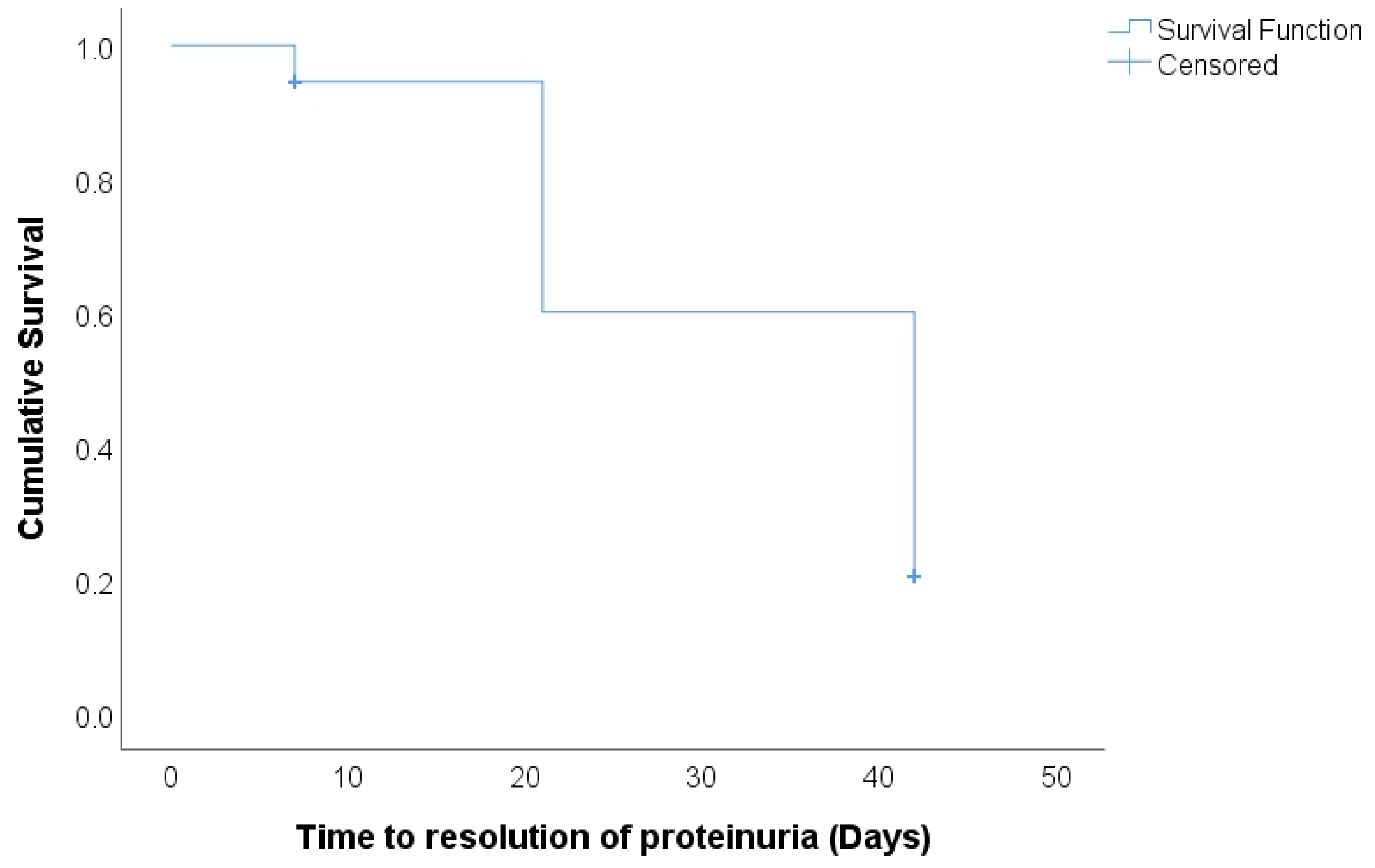

Figure 